\title{
Development of Visible Light-Responsive Photocatalysts
}

\author{
Jinlong Zhang, ${ }^{1}$ Masaya Matsuoka, ${ }^{2}$ Jae Sung Lee, ${ }^{3}$ and Shifu Chen ${ }^{4}$ \\ ${ }^{1}$ Key Lab for Advanced Materials and Institute of Fine Chemicals, East China University of Science and Technology, 130 Meilong Road, \\ Shanghai 200237, China \\ ${ }^{2}$ Department of Applied Chemistry, Graduate School of Engineering, Osaka Prefecture University, 599-8531 Osaka, Japan \\ ${ }^{3}$ Eco-friendly Catalysis and Energy Laboratory (NRL), Department of Chemical Engineering, Pohang University of Science and \\ Technology (POSTECH), Pohang 790784, Republic of Korea \\ ${ }^{4}$ Department of Chemistry, Huaibei Coal Normal College, Anhui, Huaibei 235000, China
}

Correspondence should be addressed to Jinlong Zhang, jlzhang@ecust.edu.cn

Received 20 December 2011; Accepted 20 December 2011

Copyright ( 2012 Jinlong Zhang et al. This is an open access article distributed under the Creative Commons Attribution License, which permits unrestricted use, distribution, and reproduction in any medium, provided the original work is properly cited.

Photocatalysis has received considerable attention because of its promising applications such as in photocatalytic degradation of organic pollutants, photocatalytic dissociation of water, solar energy conversion, and disinfection. As an important semiconductor, photocatalytic materials, titania has been attracting the worldwide attention due to its good chemical stability, insolubility in water, and nontoxic, low cost, and readily available raw materials. It has become a hot topic in photocatalysis scopes that how to expand the spectral response range and improve the photocatalysis quantum efficiency of photocatalysts.

Of course, the selected topics and papers are not an exhaustive representation of the area of visible lightresponsive photocatalysts. Nonetheless, they represent the rich and many-faceted knowledge, that we have the pleasure of sharing with the readers. We would like to thank the authors for their excellent contributions and patience in assisting us. Finally, the fundamental work of all reviewers on these papers is also very warmly acknowledged.

This special issue contains twenty nine papers, where two reviews are related to development of visible lightresponsive sensitized photocatalysts. Nine papers are dealing with the doping or codoping $\mathrm{TiO}_{2}$ photocatalysts. Six papers are regarding the composite photocatalysts. Two papers are related to modified photocatalysts by deposition of noble metal. Three papers are about the preparation of photocatalytic film. Six papers belong to the non- $\mathrm{TiO}_{2}$ photocatalysts. Finally, one paper addresses photocatalytic degradation of pesticides in natural water.

In the paper entitled "Development of visible lightresponsive sensitized photocatalysts," D. Pei and J. Luan present a review of studies about the visible-light-promoted photodegradation of the contaminants and energy conversion with sensitized photocatalysts. Herein authors study mechanism, physical properties, synergism effect of the sensitized photocatalysts, and the method for enhancing the photosensitized effect.

In the paper entitled "An enthusiastic glance in to the visible responsive photocatalysts for energy production and pollutant removal with special emphasis on titania," Z. Yaakob et al. present some of the recently published papers on visible responsive photocatalysts. The influence of various metal oxides and their sulfides on energy production and pollutant removal are presented with special emphasis on titania photocatalysts. A keen look into the photoactivity titania for various pollutant degradation, modified titania systems, physical and chemical characteristics are employed at this juncture.

In the paper entitled "Photocatalytic degradation of phenolics by $N$-doped mesoporous titania under Solar radiation," S. S. Rayalu et al. present preparation of nitrogen doped mesoporous titania by templating method using chitosan. This biopolymer chitosan plays the dual role of acting as a template (which imparts mesoporosity) and precursor for nitrogen. The doping of nitrogen into $\mathrm{TiO}_{2}$ lattice and its state is substantiated and measured by XPS. The photocatalytic activity of the prepared $\mathrm{N}$-doped mesoporous titania for phenol and $o$-chlorophenol degradation is investigated under solar and artificial radiation.

In the paper entitled "Visible-light photodegradation of dye on co-doped titania nanotubes prepared by hydrothermal synthesis," Chien-Te Hsieh et al. deal with preparation of 
highly porous codoped $\mathrm{TiO}_{2}$ nanotubes from a hydrothermal treatment and investigate their photocatalytic activity to photodecompose methylene blue (MB) in liquid phase under visible light irradiation.

The research of A. Nishimura et al. entitled " $\mathrm{CO}_{2}$ reforming characteristics under visible light response of Cr-or Ag-doped $\mathrm{TiO}_{2}$ prepared by sol-gel and dip-coating process" presents the preparation of Cr- or Ag-doped $\mathrm{TiO}_{2}$ film by solgel and dip-coating process and study their photocatalytic activity for $\mathrm{CO}_{2}$ reforming under the visible light.

In the paper entitled "Photocatalytical properties and theoretical analysis of $\mathrm{N}, \mathrm{Cd}$-codoped $\mathrm{TiO}_{2}$ synthesized by thermal decomposition method," X. Zhao et al. present the preparation of $\mathrm{N}$, Cd-codoped $\mathrm{TiO}_{2}$ by thermal decomposition method. The products represented good performance in photocatalytic degradation of methyl orange. The effect of the incorporation of $\mathrm{N}$ and $\mathrm{Cd}$ on electronic structure and optical properties of $\mathrm{TiO}_{2}$ are studied by first-principle calculations based on density functional theory (DFT).

There is also the paper by Tang et al. "Nitrogen-doped $\mathrm{TiO}_{2}$ photocatalyst prepared by mechanochemical method: doping mechanisms and visible photoactivity of pollutant degradation." Nitrogen-doped $\mathrm{TiO}_{2}\left(\mathrm{~N} / \mathrm{TiO}_{2}\right)$ photocatalysts are prepared using a mechanochemical method with raw amorphous $\mathrm{TiO}_{2}$ as precursors and various nitrogenous compounds doses $\left(\mathrm{NH}_{4} \mathrm{~F}, \mathrm{NH}_{4} \mathrm{HCO}_{3}, \mathrm{NH}_{3} \cdot \mathrm{H}_{2} \mathrm{O}\right.$, $\mathrm{NH}_{4} \mathrm{COOCH}_{3}$, and $\mathrm{CH}_{4} \mathrm{~N}_{2} \mathrm{O}$ ). Their photocatalytical activities were evaluated with the degradation of $\mathrm{p}$-nitrophenol and methyl orange under UV or sunlight irradiation. The catalysts have a strong visible light absorption which is corresponding to doped nitrogen and consequent oxygen deficient.

In the paper entitled "Effect of electronegativity and charge balance on the visible-light-responsive photocatalytic activity of nonmetal doped anatase $\mathrm{TiO}_{2}$," Y. Dai et al. investigate the origin of visible light absorption and photocatalytic activity of nonmetal doped anatase $\mathrm{TiO}_{2}$ in details in this work based on density functional theory calculations. Their results indicate that the electronegativity is of great significance in the band structures, which determines the relative positions of impurity states induced by the doping species, and further influences the optical absorption and photocatalytic activities of doped $\mathrm{TiO}_{2}$. The effect of charge balance on the electronic structure is also discussed, and it is found that the charge-balance structures may be more efficient for visiblelight photocatalytic activities.

In the paper entitled "Photocatalytic activity and characterization of carbon-modified titania for visible-light-active photodegradation of nitrogen oxides," C.- $\mathrm{H}$. Huang et al. present the preparation of carbon-modified titania powders, which are prepared by impregnation method using a commercial available titania powder, Hombikat UV100, as matrix material while a range of alcohols from propanol to hexanol are used as precursors of carbon sources. Rising the carbon number of alcoholic precursor molecule, the modified titania shows increasing visible activities of $\mathrm{NO}_{x}$ photodegradation.

In the paper entitled "One-step cohydrothermal synthesis of nitrogen-doped titanium oxide nanotubes with enhanced visible light photocatalytic activity," T.-C. Hsu et al. present a kind of nitrogen-doped $\mathrm{TiO}_{2}$ nanotubes synthesized using commercial titania P25 as raw material by a facile P25/urea cohydrothermal method, which shows enhanced visible light photocatalytic activity. The nitrogen content and surface area, rather than the crystallinity is found to be the crucial factors in affecting the photocatalytic efficiency of the nitrogen-doped $\mathrm{TiO}_{2}$ nanotubes.

In the paper entitled "Highly active rare-earth metal La-doped photocatalysts: fabrication, characterization, and their photocatalytic activity," S. Anandan et al. present the investigation of highly active La-doped $\mathrm{TiO}_{2}$ nanoparticles with different proportion of La content for the degradation of MCP in aqueous solution. It is observed that the rate of degradation of MCP over La-doped $\mathrm{TiO}_{2}$ increases with increasing La loading. $1.0 \mathrm{wt} \% \mathrm{La}$-doped $\mathrm{TiO}_{2}$ is found to be the most active among all the catalysts, which shows high relative photonic efficiencies. The effects of electron trapping by lanthanum metal ions, particle size, surface area, and surface roughness of the photocatalysts are supposed to be the reason for the enhanced activity.

In the paper entitled "Preparation, characterization, and photocatalytic property of $\mathrm{Cu}_{2} \mathrm{O}-\mathrm{TiO}_{2}$ nanocomposite," $\mathrm{M}$. Zhang and L. Li present a serial of $\mathrm{Cu}_{2} \mathrm{O}-\mathrm{TiO}_{2}$ nanocomposits with high visible light photocatalytic activity for the degradation of methyl orange, which is prepared by the homogeneous hydrolysation, followed by the solvothermal crystallization and ethylene glycol-thermal reduction process, respectively. The prepared $\mathrm{Cu}_{2} \mathrm{O}-\mathrm{TiO}_{2}$ nanocomposites exhibit higher photocatalytic activities for the decomposition of $\mathrm{MO}$ than the pure $\mathrm{Cu}_{2} \mathrm{O}$ and the commercial Degussa P25 under visible light irradiation.

In the paper entitled " $\mathrm{AgBr}$ coupled $\mathrm{TiO}_{2}$ : a visible heterostructured photocatalyst for degrading dye pollutants," Liu et al. present a series of $\mathrm{AgBr} / \mathrm{TiO}$ 仿otocatalysts with heterojunction structure and high-visible-light photocatalytic activity, which is synthesized using $\mathrm{Ti}\left(\mathrm{OC}_{4} \mathrm{H}_{9}\right)_{4}, \mathrm{KBr}$ and $\mathrm{AgNO}_{3}$ as precursors. It is found that the coupled $\mathrm{AgBr} / \mathrm{TiO}{ }_{2}$ shows a stable and enhanced photodegradation rate of methylene blue under visible light irradiation, compared with the noncoupled photocatalysts of $\mathrm{AgBr}, \mathrm{AgBr} / \mathrm{P} 25$ and $\mathrm{P} 25$. The synergetic effect of heterostructured $\mathrm{AgBr} / \mathrm{TiO}_{2}$ is responsible for the strongest absorption in whole UV-vis light region.

The research of Z. Liu et al. entitled "Hierarchical $\mathrm{CuO} / \mathrm{ZnO}$ membranes for environmental applications under the irradiation of visible light" studies a new kind of high active hierarchical $\mathrm{CuO} / \mathrm{ZnO}$ nanomaterial prepared using a facile process, which has a great potential in environmental applications with solar visible light. This novel $\mathrm{CuO} / \mathrm{ZnO}$ membrane shows improved photodegradation of contaminants and antibacterial activity under the irradiation of visible light. It is found that the special hierarchical nanostructure of $\mathrm{CuO} / \mathrm{ZnO}$ is in favour of enhancing light utilization rate, enlarging specific surface and reducing the recombination of electrons and holes at the interfacial between $\mathrm{CuO}$ and $\mathrm{ZnO}$, which is the reason for the high photocatalytic activity.

In the paper entitled "Photocatalytic oxidation of gaseous isopropanol using visible-light active silver vanadates/SBA-15 
composite," C.-M. Huang et al. present an environmentally friendly visible-light driven photocatalyst, silver vanadates/SBA-15, which is prepared through an incipient wetness impregnation procedure with silver vanadates (SVO). All the composites loaded with various amount of SVO inherit the higher adsorption capacity and larger mineralization yield than those of P25 and pure SVO, which is resulting from a favorable crystalline phase combined with the high intensities of Brønsted and Lewis acids.

In the paper entitled "Sol-gel-hydrothermal synthesis of the heterostructured $\mathrm{TiO}_{2} / \mathrm{N}-\mathrm{Bi}_{2} \mathrm{WO}_{6}$ composite with highvisible-light and ultraviolet-light-induced photocatalytic performances," Z.-H. Huang et al. present a heterostructured $\mathrm{TiO}_{2} / \mathrm{N}-\mathrm{Bi}_{2} \mathrm{WO}_{6}$ composite prepared by a facile sol-gelhydrothermal method, which has a high UV and visible light photocatalytic performance. The $\mathrm{TiO}_{2} / \mathrm{N}-\mathrm{Bi}_{2} \mathrm{WO}_{6}$ composites exhibit much higher photocatalytic performances than $\mathrm{TiO}_{2}$ as well as $\mathrm{Bi}_{2} \mathrm{WO}_{6}$, owing to the effective electron-hole separations at the interfaces of the two semiconductors.

In the paper entitled "Preparation of $\mathrm{TiO}_{2}$-fullerene composites and their photocatalytic activity under visible light," Ken-ichi Katsumata et al. present the preparation and characterization of $\mathrm{TiO}_{2}$-fullerene composites which are prepared by a solution process. It is found that the rutileC60 exhibit higher activity than the rutile under visible light, resulting from the transfer of photogenerated electrons from the C60 to the rutile under visible light irradiation.

The research of J. J. Murcia et al. entitled "Photocatalytic ethanol oxidative dehydrogenation over $\mathrm{Pt} / \mathrm{TiO}_{2}$ : effect of the addition of blue phosphors" investigates the effect of blue phosphors on the ethanol oxidative dehydrogenation over $\mathrm{Pt} / \mathrm{TiO}_{2}$ photocatalyst. It is found that the blue phosphors produced an increase in the level of ethanol conversion over the $\mathrm{Pt} / \mathrm{TiO}_{2}$ catalyst keeping at the same time the high selectivity to acetaldehyde.

In the paper entitled "Application of Pt/CdS for the photocatalytic flue gas desulfurization," W. Yao et al. design a photocatalytic flue gas desulfurization technology to control emissions of $\mathrm{SO}_{2}$ from the combustion of fossil fuels. CdS loaded with Pt are selected as the model photocatalyst for the photocatalytic flue gas desulfurization, and the factors influencing the rate of hydrogen production and ammonia sulfite solution oxidation are detected in this paper.

The research of Y.-H. Chen and K.-J. Tu entitled "Thickness dependent on photocatalytic activity of hematite thin films" obtains a result that the photocatalytic activity of hematite films increases with the increasing film thickness, which is because the hematite film with a thicker thickness has a rougher surface, providing more reaction sites for photocatalysis. In addition, the lower band gap of a hematite film would generate more electron-hole pairs under visiblelight illumination to enhance the photocatalytic efficiency.

In the paper entitled "Photoresponse of visible light active $C M-n-\mathrm{TiO}_{2}, H M-n-\mathrm{TiO}_{2}, C M-n-\mathrm{Fe}_{2} \mathrm{O}_{3}$, and $C M-p-W_{3}$ towards water splitting reaction," Y. A. Shaban and S. U. M. Khan summarize their studies on thin film photoelectrodes of Visible light active carbon modified titanium oxides (CM$\mathrm{n}$ - $\mathrm{TiO}_{2}$ ); Visible light active hydrogen modified n-type titanium oxide $\left(\mathrm{HM}-\mathrm{n}-\mathrm{TiO}_{2}\right)$ thin films; carbon modified iron oxides (CM-n- $\left.\mathrm{Fe}_{2} \mathrm{O}_{3}\right)$ thin films; visible light active carbon modified p-type tungsten oxides $\left(\mathrm{CM}\right.$-p- $\left.\mathrm{WO}_{3}\right)$ thin film.

In the paper entitled "Preparation of porous $\mathrm{F}-\mathrm{WO}_{3} / \mathrm{TiO}_{2}$ films with visible-light photocatalytic activity by microarc oxidation," K.-R. Wu et al. present a kind of porous F$\mathrm{WO}_{3} / \mathrm{TiO}_{2}\left(\mathrm{mTiO}_{2}\right)$ films prepared on titanium sheet substrates using microarc oxidation (MAO) technique, which shows an enhanced photocatalytic degradation of dye under UV and visible light irradiation, owing to its high specific surface area from the porous microstructure.

In the paper entitled "Silver orthophosphate immobilized on flaky layered double hydroxides as the visible-lightdriven photocatalysts," Q. Zhang et al. present a visiblelight driven photocatalyst $\mathrm{FLDH} / \mathrm{Ag}_{3} \mathrm{PO}_{4}$ fabricated by the coprecipitation method. It is found that the photocatalytic activities of $\mathrm{Ag}_{3} \mathrm{PO}_{4}$ immobilized on the surface of FLDH are significantly enhanced for the degradation of acid red $\mathrm{G}$ under visible light irradiation compared to bare $\mathrm{Ag}_{3} \mathrm{PO}_{4}$.

In the paper entitled "Photodegradation of malachite green by nanostructured $\mathrm{Bi}_{2} \mathrm{WO}_{6}$ visible light induced photocatalyst," Zhang et al. study the photodegradation of malachite green by the $\mathrm{Bi}_{2} \mathrm{WO}_{6}$ photocatalyst for the first time. The effects of the concentration of malachite green, the $\mathrm{pH}$ value, and the concentration of $\mathrm{Bi}_{2} \mathrm{WO}_{6}$ on the photocatalytic efficiency are investigated in this paper.

In the paper entitled "Synthesis, property characterization, and photocatalytic activity of novel visible light-responsive photocatalyst $\mathrm{Fe}_{2} \mathrm{BiSbO}_{7}$," J. Luan and $\mathrm{Z}$. Hu present the preparation and characterization of visible light induced photocatalyst $\mathrm{Fe}_{2} \mathrm{BiSbO}_{7}$, which is synthesized by a solidstate reaction method for the first time. It is found that the $\mathrm{Fe}_{2} \mathrm{BiSbO}_{7}$ possesses higher photocatalytic degradation of $\mathrm{MB}$ under visible light irradiation, compared with $\mathrm{Bi}_{2} \mathrm{InTaO}_{7}$ or pure $\mathrm{TiO}_{2}$ or $\mathrm{N}$-doped $\mathrm{TiO}_{2}$. The possible photocatalytic degradation pathway of $\mathrm{MB}$ over $\mathrm{Fe}_{2} \mathrm{BiSbO}_{7}$ is obtained in this paper.

In the paper entitled " $\mathrm{Sm}_{2} \mathrm{FeTaO}_{7}$ photocatalyst for degradation of indigo carmine dye under solar light irradiation," L. $\mathrm{M}$. Torres-Martínez et al. study the degradation of indigo carmine dye over $\mathrm{Sm}_{2} \mathrm{FeTaO}_{7}$ pyrochlore-type compound, which is synthesized by using conventional solid state reaction and sol-gel method. It is found that the solar-lightinduced degradation active of sol-gel photocatalyst is 8 times to the active of solid state. When $\mathrm{Sm}_{2} \mathrm{FeTaO}_{7}$ is impregnated with $\mathrm{CuO}$ as cocatalyst the photocatalytic activity is increased because $\mathrm{CuO}$ acts as electron trap decreasing electron-hole pair recombination rates.

In the paper entitled "Photosensitized oxidation of 9,10dimethylanthracene on dye-doped silica composites," M. A. Valenzuela et al. present a series of cationic dyes, methylene blue (MB), safranin $\mathrm{O}(\mathrm{SF})$, toluidine blue (TB), and neutral red (NR) successfully incorporated into a silica matrix by using ultrasound irradiation during the Stöber process. Among these four different types of dye-doped silica composites, the $\mathrm{SiO}_{2}-\mathrm{SF}$ composite shows the most efficient delivery of singlet oxygen. This result is explained in terms of a higher dispersion of the SF on the silica matrix.

In the paper entitled "Synthesis, characterization, and evaluation of boron-doped iron oxides for the photocatalytic 
degradation of atrazine under visible light," D. Zhu et al. investigate the photocatalytic degradation of atrazine by boron-doped iron oxides under visible light irradiation. Boron-doped goethite and hematite are successfully prepared by sol-gel method. It is found that the B-doped iron oxides shows higher atrazine degradation rate than that of pristine iron oxides, and the B-doped goethite exhibits better photocatalytic activity than B-doped hematite. The better crystal structure, larger BET surface area, enhanced light absorption ability, and narrowed band-gap energy induced by the B-doping are responsible for the high photocatalytic activity.

In the paper entitled "Photocatalytic degradation of pesticides in natural water: effect of hydrogen peroxide," N. Miguel et al. evaluate the effectiveness of photocatalytic treatment with titanium dioxide in the degradation of 44 organic pesticides analyzed systematically in the Ebro river basin (Spain). The effect of the addition of hydrogen peroxide in this treatment is studied in this paper. It is found that the addition of hydrogen peroxide could increase the average degradation of pesticides. The pesticides which are best degraded are parathion methyl, chlorpyrifos, $\alpha$-endosulphan, 3,4dichloroaniline, 4-isopropylaniline, and dicofol, while the worst degraded are HCHs, endosulphan-sulphate, heptachlors epoxide, and 4,4' -dichlorobenzophenone.

Jinlong Zhang

Masaya Matsuoka

Jae Sung Lee

Shifu Chen 


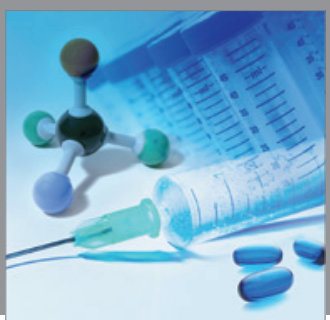

International Journal of

Medicinal Chemistry

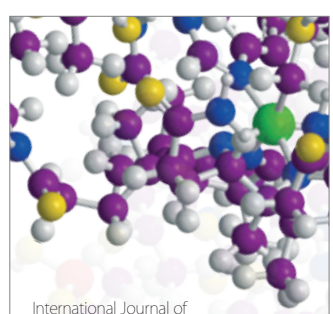

Carbohydrate Chemistry

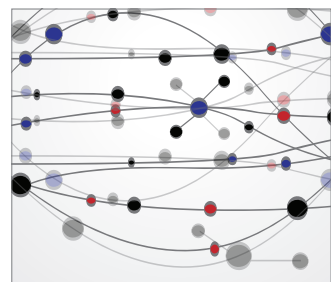

The Scientific World Journal
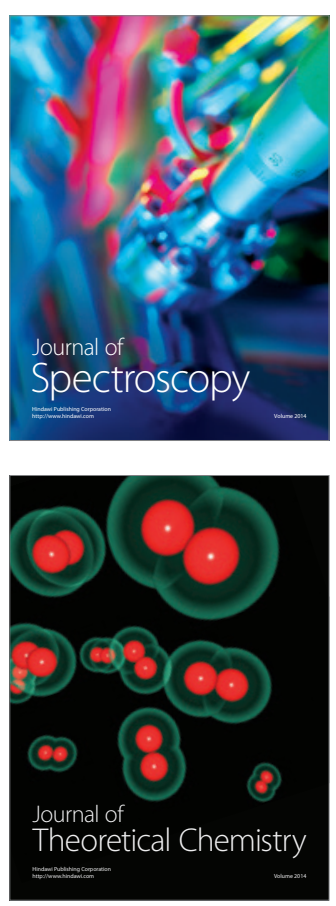
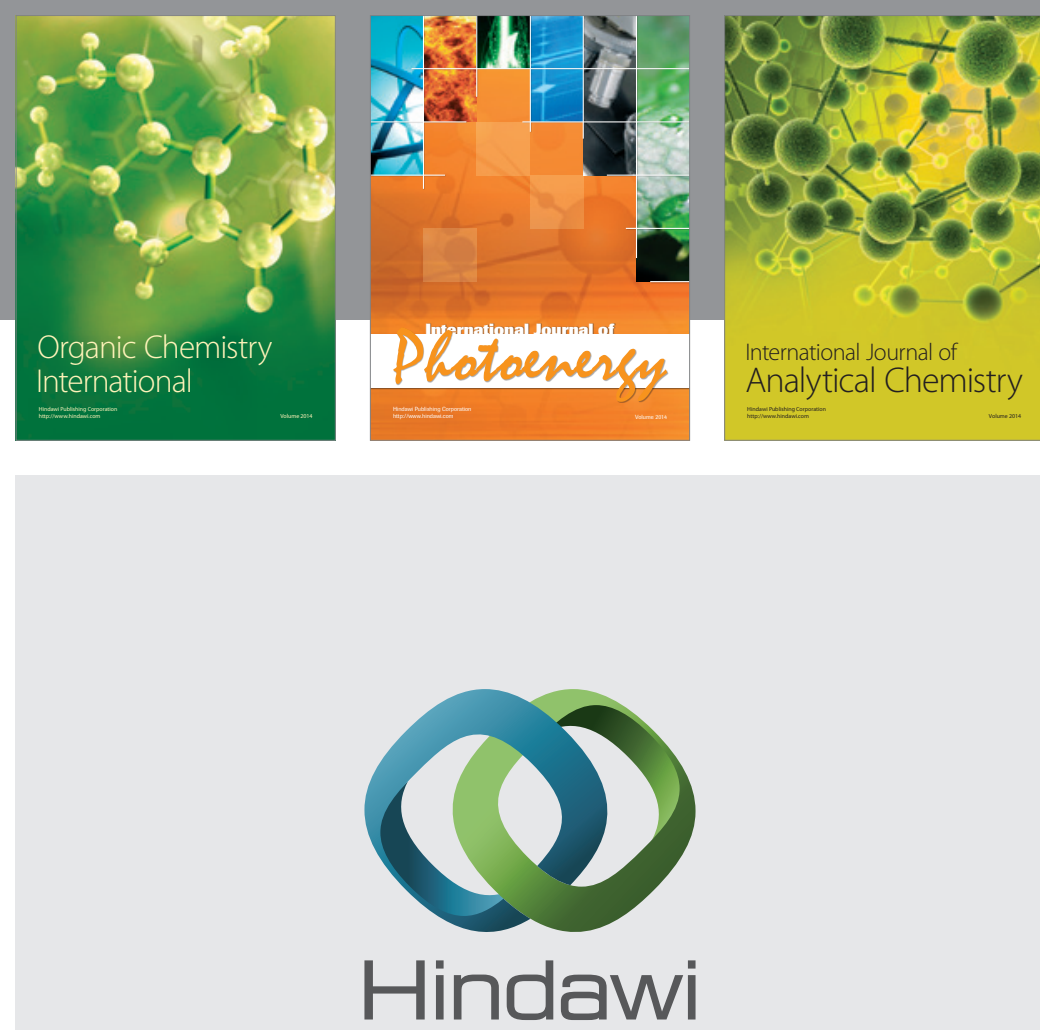

Submit your manuscripts at

http://www.hindawi.com
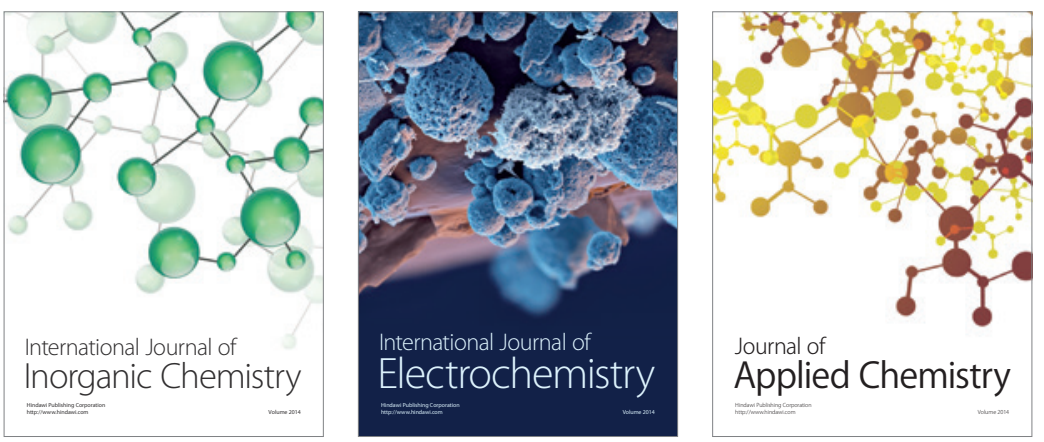

Journal of

Applied Chemistry
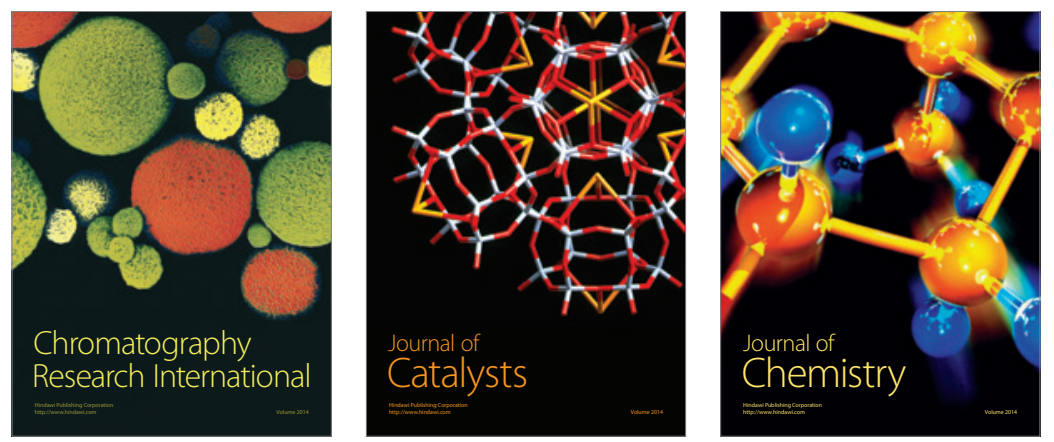
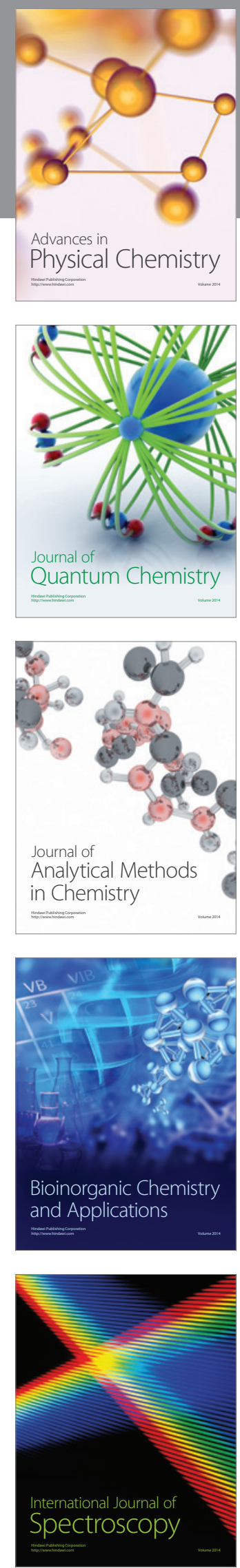